\title{
Dry Powder Conditioning Mixing
}

National Cancer Institute

\section{Source}

National Cancer Institute. Dry Powder Conditioning Mixing. NCI Thesaurus. Code C113024.

Mixing of dry ing redients with the addition of a small amount of liquid, done to increase binding capability. 